\title{
Front Matter: Volume 11842
}

, "Front Matter: Volume 11842," Proc. SPIE 11842, Applications of Digital Image Processing XLIV, 1184201 (8 October 2021); doi: 10.1117/12.2606458

SPIE Event: SPIE Optical Engineering + Applications, 2021, San Diego, California, SPIE. United States 


\title{
PROCEEDINGS OF SPIE
}

\section{Applications of Digital Image Processing XLIV}

\author{
Andrew G. Tescher \\ Touradj Ebrahimi \\ Editors
}

1-5 August 2021

San Diego, California, United States

Sponsored and Published by

SPIE 
The papers in this volume were part of the technical conference cited on the cover and title page. Papers were selected and subject to review by the editors and conference program committee. Some conference presentations may not be available for publication. Additional papers and presentation recordings may be available online in the SPIE Digital Library at SPIEDigitalLibrary.org.

The papers reflect the work and thoughts of the authors and are published herein as submitted. The publisher is not responsible for the validity of the information or for any outcomes resulting from reliance thereon.

Please use the following format to cite material from these proceedings:

Author(s), "Title of Paper," in Applications of Digital Image Processing XLIV, edited by Andrew G. Tescher, Touradj Ebrahimi, Proc. of SPIE 1 1842, Seven-digit Article CID Number (DD/MM/YYYY); (DOI URL).

ISSN: 0277-786X

ISSN: 1996-756X (electronic)

ISBN: 9781510645226

ISBN: 9781510645233 (electronic)

Published by

SPIE

P.O. Box 10, Bellingham, Washington 98227-0010 USA

Telephone +1 3606763290 (Pacific Time)

SPIE.org

Copyright (C) 2021 Society of Photo-Optical Instrumentation Engineers (SPIE).

Copying of material in this book for internal or personal use, or for the internal or personal use of specific clients, beyond the fair use provisions granted by the U.S. Copyright Law is authorized by SPIE subject to payment of fees. To obtain permission to use and share articles in this volume, visit Copyright Clearance Center at copyright.com. Other copying for republication, resale, advertising or promotion, or any form of systematic or multiple reproduction of any material in this book is prohibited except with permission in writing from the publisher.

Printed in the United States of America by Curran Associates, Inc., under license from SPIE.

Publication of record for individual papers is online in the SPIE Digital Library.

\section{SPIE. DIGITAL \\ SPIEDigitalLibrary.org}

Paper Numbering: A unique citation identifier (CID) number is assigned to each article in the Proceedings of SPIE at the time of publication. Utilization of CIDs allows articles to be fully citable as soon as they are published online, and connects the same identifier to all online and print versions of the publication. SPIE uses a seven-digit CID article numbering system structured as follows:

- The first five digits correspond to the SPIE volume number.

- The last two digits indicate publication order within the volume using a Base 36 numbering system employing both numerals and letters. These two-number sets start with 00, 01, 02, 03 , 04, 05, 06, 07, 08, 09, OA, OB ... 0Z, followed by 10-1Z, 20-2Z, etc. The CID Number appears on each page of the manuscript. 


\section{Contents}

\section{ARTIFICIAL INTELLIGENCE IN IMAGE AND VIDEO COMPRESSION}

1184203 Quality-aware CNN-based in-loop filter for video coding [1 1842-1]

1184204 A study of deep image compression for YUV420 color space [11842-2]

1184205 Bi-directional prediction for end-to-end optimized video compression [1 1842-3]

1184206 Multi-hypothesis inspired super-resolution for compression distorted screen content image [1 1842-4]

$1184207 \quad$ Learning-based encoder algorithms for VVC in the context of the optimized VVenC implementation [1 1842-5]

VIDEO PROCESSING FOR USER-GENERATED CONTENT

1184208 Machine learning based tuning of encoding parameters for UGC video coding optimizations [1 1842-8]

1184209 On quality control of user-generated-content (UGC) compression [1 1842-10]

11842 OA Subjective and objective study of sharpness enhanced UGC video quality [1 1842-11]

\section{ADVANCED VIDEO COMPRESSION}

$11842 \mathrm{OB} \quad$ An end-to-end distributed video analytics system using HEVC annotated regions SEI message [11842-12]

$118420 \mathrm{C}$ Simplified carriage of MPEG immersive video in HEVC bitstream [1 1842-13]

11842 OD Implementation of film-grain technology within VVC [11842-14]

11842 OF VMAF and variants: towards a unified VQA [1 1842-16]

11842 OG Bandlimited wireless video communications over lossy channels [1 1842-17]

$11842 \mathrm{OH} \quad$ VVenC: an open optimized VVC encoder in versatile application scenarios [11842-18] 
11842 Ol Overview of baseline profile in MPEG-5 essential video coding standard [1 1842-19]

11842 OJ HDR video coding for aerial videos with VVC and AV1 [1 1842-20]

IMAGING AND INFORMATION CHAOS

11842 OK Fake-buster: a lightweight solution for deepfake detection [1 1842-23]

11842 OL JPEG Fake Media: a provenance-based sustainable approach to secure and trustworthy media annotation [1 1842-24]

11842 OM Adopting the JPEG universal metadata box format for media authenticity annotations [1 1842-25]

$118420 \mathrm{~N} \quad$ Framing photos in the digital dark age: towards a socio-technological 'ecology of images' [1 1842-26]

IMAGE AND VIDEO COMPRESSION

$1184200 \quad$ Per-clip and per-bitrate adaptation of the Lagrangian multiplier in video coding [1 1842-27]

11842 OP DCST: a data-driven color/spatial transform-based image coding method [11842-28]

$118420 Q \quad$ Content adaptive video compression for autonomous vehicle remote driving [1 1842-29]

11842 OR Frame synthesis for video compression [1 1842-30]

11842 OS Learning residual coding for point clouds [11842-31]

11842 OT Towards much better SVT-AV1 quality-cycles tradeoffs for VOD applications [1 1842-32]

\section{APPLICATIONS OF VISUAL PERCEPTION IN IMAGING}

11842 OU Training compression artifacts reduction network with domain adaptation [1 1842-33]

11842 OV Study on deep CNN as preprocessing for video compression [1 1842-34]

11842 OW The effect of degradation on compressibility of video [1 1842-35]

11842 OX A differentiable VMAF proxy as a loss function for video noise reduction [1 1842-36] 
11842 OY Review of subjective quality assessment methodologies and standards for compressed images evaluation [11842-37]

$118420 Z$ Fundamental relationships between subjective quality, user acceptance, and the VMAF metric for a quality-based bit-rate ladder design for over-the-top video streaming services [1 1842-38]

\section{APPLICATIONS OF BIOMEDICAL IMAGING}

$1184210 \quad$ Image-based autofocusing algorithm applied in image fusion process for optical microscope [11842-39]

$1184211 \quad$ Evaluation of deep learning techniques for the detection of pulmonary nodules in computer tomography scans [11842-40]

1184212 Evaluation of segmentation techniques for cell tracking in confocal microscopy images [11842-41]

1184213 Preprocessing fast filters and mass segmentation for mammography images [11842-42]

1184214 Evaluation of filtering techniques for cell tracking in confocal microscopy images [1 1842-43]

1184215 MTS image analyzer: a software tool to identify mesial temporal sclerosis in MRI images [11842-44]

1184216 Cartesian function of glycerin diffusion over ex-vivo porcine skin samples using multiple sequential THz images [1 1842-45]

\section{IMAGING SECURITY AND ANALYSIS}

$1184217 \quad$ Facial recognition system for security access control [11842-46]

1184218 Towards a secure and trustworthy imaging with non-fungible tokens [11842-47]

$118421 \mathrm{~A}$ Towards image denoising in the latent space of learning-based compression [1 1842-49]

11842 1B Design and implementation of augmented reality system for paper media based on ARtoolKit [11842-50]

\section{D IMAGING AND AUGMENTED-REALITY APPLICATIONS}

11842 1C 3D computer-generated holograms for augmented reality applications in medical education [11842-51]

11842 1D High-speed simultaneous measurement of depth and normal for real-time 3D reconstruction [11842-52] 
IMAGE ANALYSIS TOOLS AND TECHNIQUES

$118421 \mathrm{E} \quad$ Phase congruency implementation in ImageJ using Radix-2 FFT [1 1842-55]

11842 1F Inpainting method based on variational calculus and sparse matrices [1 1842-56]

$1184216 \quad$ Study of phase congruency quantization function properties for image edge detection [1 1842-57]

$118421 \mathrm{H} \quad$ Efficient Java implementation of image cloning method based on gradient processing [1 1842-58]

$1184211 \quad$ Evaluation of panchromatic and multispectral image fusion methods using natural images [1 1842-60]

\section{IMAGING SYSTEMS}

$118421 \mathrm{~K} \quad$ VehiPose: a multi-scale framework for vehicle pose estimation [1 1842-63]

$118421 \mathrm{M} \quad$ An extensible framework for video ASIC development and validation at Facebook scale [1 1842-66]

$118421 \mathrm{~N} \quad$ Towards super resolution in the compressed domain of learning-based image codecs [1 1842-67]

\section{POSTER SESSION}

11842 1B Design and implementation of augmented reality system for paper media based on ARtoolKit [1 1842-50]

1184210 Design and implementation of interactive game based on augmented reality [11842-53]

11842 IP ICP algorithm based on stochastic approach [1 1842-54]

$118421 Q \quad$ Fast algorithm of 3D object volume calculation from point cloud [1 1842-68]

$118421 \mathrm{R} \quad$ Fast 3D object pose normalization for point cloud [1 1842-69]

11842 is Fast 3D object symmetry detection for point cloud [1 1842-70]

$118421 \mathrm{X} \quad$ Binarization method for chromosomal analysis of primitive plants: the case of Zamia tolimensis and Zamia huilensis (Cycadales, Zamiaceae) [1 1842-75] 
$1184221 \quad$ Regularized variational functional use a rough alignment for point clouds registration [1 1842-79]

1184222 Convolutional neural network for 3D point clouds matching [11842-80]

1184227 Contactless robust 3D palm-print identification using photometric stereo [1 1842-85]

$1184229 \quad$ Fast approximate geodesic distance on point cloud [1 1842-87]

11842 2B New method for digitization and manipulation of textile molds based on image processing [1 1842-89]

11842 2D Analysis of lung cancer clinical diagnosis based on nodule detection from computed tomography images [11842-91]

$118422 \mathrm{E} \quad$ Development and validation of a novel automated method for quantification of choroidal thickness in age-related macular degeneration [1 1842-92]

$118422 \mathrm{~F} \quad$ Gradient direction analysis for contour tracking and local non maximum suppression [1 1842-93]

$118422 \mathrm{G}$ Transform-based quality assessment for enhanced image [1 1842-94] 
Proc. of SPIE Vol. 11842 1184201-8 Downloaded From: https://www.spiedigitallibrary.org/conference-proceedings-of-spie on 25 Apr 2023
Terms of Use: https://www.spiedigitallibrary.org/terms-of-use 